\title{
3 UNIVERSIDAD, SEDE DE LA RAZÓN
}

Dr. Hernán Malo González, S I

\section{1.- CONSIDERACIÓN INTRODUCTORIA}

\section{El problema del acuerdo en los contenidos conceptuales}

El momento en que discutimos un problema sobre todo de índole humana, la crisis, que él supone, presupone otra crisis: la de la comunicación y por tanto de la palabra. Es menester arrancar de un acuerdo, bien sea provisional, sobre el contenido mínimo de ciertos términos; de lo contrario la discusión es inviable (se entiende la discusión como diálogo profundo, no como dos monólogos superpuestos). Y esto no es fácil, y lo es menos en tratándose de gente pensante, como es la universitaria. Pueden adoptarse dos vías: o la imposición apriorística (digamos dogmática) de determinados contenidos conceptuales o la adopción a manera de hipótesis de los mismos. La primera se descarta entre personas, que ejercen precisamente la crítica de la razón o de las razones. No queda sino la segunda. Con ella echará a andar el diálogo y en el diálogo, que es factor dinámico de la razón y de sí mismo, surgirá el esclarecimiento del problema. Al final la hipótesis tal vez se confirme o quizás caiga.

Hay dos conceptos, en torno a los cuales debe girar este artículo: el de universidad y el de razón. El acuerdo sobre ellos puede volverse tanto más problemático, cuanto que va a surgir o puede surgir la discusión entre personas que, al representar visiones de la realidad no afines, posiblemente están dando contenidos muy diversos a términos idénticos.

He querido subrayar esto, para dejar en claro lo inevitable de cierta parcialidad, que puede revestir mi escrito, para justificar la explicación, que voy a hacer de los términos mencionados arriba, explicación que para varios puede ser hipótesis discutible; para en fin recalcar desde el primer momento la gran aporía del quehacer universitario en cuanto diálogo o dialéctica de la razón. 


\section{2.- PRENOTANDOS SOBRE LA RAZÓN}

\section{A.-Análisis sumario del término razón en la historia de la Filosofía}

No se trata de una breve historia de la razón en la Filosofía, sino del realce de ciertos contenidos importantes de ella marcados en la historia. Dicha importancia se refiere a la descripción, que como hipótesis quiero presentar de la razón.

RAZÓN, cuyo origen inmediato latino es RATIO, abarca un espectro vastísimo de significaciones: Va desde la mente humana hasta la divina (S. Agustín dice que la ley eterna es ratio et voluntas divina ordinem naturalem observari iubens et perturbari vetans) (11). Se mueve desde la idea de mero instrumento útil del conocer humano auténtico (tal la posición vitalista antihegeliana) hasta la explicación lógica y ontológica de la realidad, como es el caso del LOGOS heraclitiano y de la razón de Hegel: afirma este último filósofo: "Die an und für sich seinde Wahrheit, welche die Vernunft ist, ist die einfache Idenittát der Subjektivitát des Begriffs und seiner Objektivitát und Allgemeinheit" (la verdad existente en sí y por sí, es decir la razón, consiste en la simple identidad de la subjetividad del concepto con su objetividad y generalidad) (12). Parece que para Hegel, al final de cuentas, razón y realidad se identifican.

Dentro de este marco, y mirada la razón ante todo como un dato del ser humano, pienso que, de entre la multitud de acepciones, algunas de ellas excluyentes de otras según filósofos y escuelas, resta un sustrato doble común: referencia al acto específico cognoscitivo del ser humano y relación de alguna índole de la explicación (a la "razón de ser") de la realidad.

A partir de estos dos contenidos sedimentarios y, dejando por cierto de lado otros conceptos de razón no rigurosamente filosóficos (v. c. la razón matemática), elaboraré un contenido más extenso de razón.

1 (1) Contra Faustum. 1. 22, C.27

2 (1) Enzyklopadie No 438. 
RATIO, como término consagrado filosófico, se incorpora al idioma latino mediante Lucrecio y Cicerón; recoge el contenido de diversos vocablos griegos, principalmente de DIANOIA NOESIS y sobre todo de LOGOS. Cicerón en su tratado de Legibus I, 10, 30, afirma: "Etenim ratio, qua una praestamus belluis, per quan.... argumentamur, refellimus, disserimus, conficimus aliquid, concludimus, certe est communis, doctrina differens, discendi quidem facultate par" (la razón, por la cual precisamente superamos a las bestias, mediante la cual argumentamos, refutamos, discurrimos, realizamos una síntesis, llegamos a conclusiones, ciertamente es común a todos, bien que haya diferencia en las doctrinas, y se equipara a la facultad de aprender).

Por tanto se instituye la razón como lo específico y diferencial del ser humano: el ZOON LOGIKON de Aristóteles se convierte, en nuestra cultura románica, en el ANIMAL RATIONALE. Siendo lo latino en este punto, como en muchísimos otros, heredero de lo helénico, veamos de la filosofía griega aquellos puntos, que tienen resonancia decisiva y constante en la evolución del pensamiento occidental:

El acto "racional" (LOGIKON) como el acto guía del ser humano se plantea en primera instancia como un problema de la aprehensión de la verdad (HE ALETHEIA). Dejando de lado al precursor Xenófanes, es Parménides quien inicia el planteamiento e impone la pauta: el hombre común vive sumido en el engaño del mundo sensible, que es aceptado como la realidad auténtica (he odos tes doxes). El hombre consciente debe hacer un esfuerzo por unificar su mente, para echar a andar por la vía de la verdad (he odos tes aletheias). En esa vía entiende que la única verdad es que es lo que es (to on): realidad una, inmutable, absolutamente simple, repleta sola y exclusivamente de "ES".

A partir de esta toma de posición parmeniana, el griego, incluido ciertamente Platón, plantea el problema del conocimiento de la verdad dentro de ciertos preceptos, que son de sumo interés y que se enumeran en los cuatro puntos siguientes:

1) La verdad es algo objetivo más bien que subjetivo: es la realidad auténtica en cuanto tal.

2) También la falsedad es algo fundamentalmente objetivo: hay un sector objetivo falso. 
3) En consecuencia el conocimiento falso, más que un error de procedimiento cognoscitivo, es la aprehensión de lo falso. Y al revés el conocimiento verdadero.

4) Por tanto, la búsqueda de la verdad en el hombre más que un asunto gnoseológico, es un reto moral: un esfuerzo por dejarse iluminar por ella.

Dentro de este planteamiento Heráclito, contemporáneo de Parménides, habla del hombre entregado a la superficialidad de la vida, confundido por las cosas múltiples, devenientes, opuestas, desligado del LOGOS (usa ya esta palabra), el cual desde nuestra hondura confiere unidad y nitidez al mundo visible. Es menester por tanto realizar un empeño constante por mantenernos en diálogo permanente con el LOGOS. No entramos en la disquisición compleja sobre su índole; baste afirmar que evidentemente engloba al entendimiento humano. Es importante acotar que esta conversión al LOGOS entraña claramente la nota de REFLEXIÓN que sin duda es lo más específico de la especificidad humana.

Platón recoge el legado y lo enriquece con proyecciones gigantescas. El asunto es tratado en la manera más profunda y completa en el libro VII de la República, que comienza con la célebre alegoría de la caverna. Siguiendo el esquema parmeniano, que señalé en los cuatro puntos, plantea el problema de la verdad como el encuentro de la misma. Para salvar el punto muerto creado por Parménides, pone entre el ser y el no-ser un mundo mezcla de ser y de no-ser; el sensible (ta doxanta). A cada uno de estos mundos corresponden formas de conocimiento cualificadas: al del ser el conocimiento verdadero, al del no-ser el conocimiento falso, al del semi-ser un conocimiento semiverdadero: la opinión (HE DOXA). Nótese que la precariedad inherente a la opinión no se debe a la falta de elementos de juicio, sino a que el objeto mismo no da más que para una opinión. La gran tarea del hombre es superar este conocimiento precario oriundo del mundo precario, que nos asedia, para enfrentarse con el del ser, el cual es el mundo de las ideas, entre las que campea el Bien. Para ello, debe encumbrarse con esfuerzo a través de los grados de la mente (incluido el discurso lógico), hasta encontrarse cara a cara con las ideas en una contemplación (THEOREIA), que no tendrá fin. La nota moral de la búsqueda de la verdad reviste en Plantón el dramatismo de una ascesis heroica: el hombre encadenado en la prisión de lo sensible tiene que salir de ella, rompiendo las 
cadenas y dando las espaldas a este mundo (el texto griego dice: Syn Ole te psyche tou gignomenou periakteon einai: con toda el alma convertirse de lo caduco) $\left(1^{3}\right)$. Subrayo el término CONVERSIÓN hacia el mundo de las ideas. El encuentro con él es doloroso. Sobrevienen las vicisitudes del enfrentamiento con las ideas: en un primer momento la ceguera desconcertante de haber visto al sol, luego el penoso adaptarse, hasta el momento de mirarlo sin pestañar. Por fin la misión de convertir a los demás, la que lleva consigo el riesgo aun de la muerte. El apóstol de las ideas puede ser (y lo es en el caso de Sócrates, por ejemplo) un MÁRTIR en el sentido de testimonio, y en el sentido más cruento del vocablo. Al fin el reto de la razón consiste en una gran opción ante la cual el hombre compromete su ser total.

He deseado subrayar esta implicación moral de la razón por su influjo enorme en el pensamiento occidental y porque con los debidos reajustes y puestas al día, representará un aspecto muy interesante del tema de fondo: UNIVERSIDAD, SEDE DE LA RAZÓN.

Aristóteles vuelve científico y más sujetivo si se quiere el asunto de la razón; lo enfoca dentro del problema del conocer psicológico, y del análisis sistemático de la realidad para elaborar la ciencia. Plantea claramente los dos niveles de conocimiento (sensible e intelectual) y estudia su concatenación gnoseológica. Hace hincapié en la RAZÓN dianoia, en el sentido específico de conocimiento racional discursivo, distinto del intuitivo. Sin embargo no suprime los otros aspectos señalados en sus predecesores helénicos.

Sin así mismo renunciar a los elementos platónicos de intelecto (en algunos puntos se los enfatiza), la gran corriente medieval de la filosofía, que tendrá un rebrote vigoroso en el siglo de oro español, al ser heredera en primera instancia de Aristóteles, continúa con el sesgo aristotélico de la razón (vinculado por lo demás a partir de entonces con la expresión literal del vocablo).

Dejemos de lado el concepto escolástico de razón como explicación (ratio suficiens) o como realidad (rationes seminales v. gr.) y ciñámonos a la razón como instrumento de conocer. Se produce una intensificación de la ratio como dianoia, es decir la facultad del discurso lógico. Dice Santo Tomás: "Etsi intellectus et ratio non sint diversae potentiae, tamen denominnatur ex diversis actibus. Intellectus enim nomen sumitur ab intima penetratione ve-

3 (1) República 518b. 
ritatis, nomen autem rationis ab inquisitione et discursu": (Si bien el intelecto y la razón no son facultades distintas, sin embargo se las denomina con referencia a diversos actos. El entendimiento se denomina así por el poder de íntima penetración de la verdad, en cambio la razón se denomina así por la nota de inquisición y de discurso") $\left(1^{4}\right)$. Y al darse preeminencia a este discurso lógico, con su rígida sujeción a cánones silogísticos y su tendencia a descuidar los contenidos intelectivos de los términos, se provoca la degeneración del nominalismo y se prepara el advenimientos del Racionalismo (he ahí una CRISIS de la razón). Este punto es importante ya que como diré más adelante habría preferido usar otro vocablo para el asunto de fondo.

La razón se racionaliza en la edad moderna. Es decir que, al menos en el campo de la filosofía, la mente humana se concibe despojada casi totalmente de elementos no lógico- discursivos. El proceso mental de estilo matemático parece ser lo privativo de la mente humana. Tal la posición de Descartes, Leibniz, Spinoza; este último escribe su ETHICA GEOMETRICE DEMONSTRATA, que representa el modelo por antonomasia del racionalismo. La RAZÓN como término y concepto se ha empobrecido y se ha revestido de una tonalidad de RACIONALISMO, de la que nunca ha podido rehacerse. Kant y Hegel en vez de superar la crisis, la acrecientan de alguna manera. Si bien Kant enriquece a la razón con un poder práctico, sin embargo acorrala a la razón pura en el terreno de lo físico-matemático.

Los síntomas de superación se manifiestan en su primera fase en una reacción antirracionalista, representada por Schelling por el romanticismo alemán, por los pioneros de la corriente vitalista francesa, y en una segunda etapa en la reintegración de la razón a la complejidad del pensamiento humano; piénsese en la riqueza humana del existencialismo. Omito, por carecer aún de perspectiva histórica, analizar el aporte a la razón de las corrientes filosóficas últimas.

4 (1) Sum Theol. II, 2, 49, 5 ad 3. 


\section{B.- PRECISIÓN DEL TERMINO}

A base del análisis anterior, defino RAZÓN como la capacidad específica del ser humano para aproximarse al mundo, interpretarlo y así disponerse en forma específicamente humana a obrar. Su instrumento más apto es el raciocinio, pero su nota más profunda es la reflexión. De lo dicho más arriba, concluyo que, dadas las adherencias racionalistas que persisten en la RAZÓN, habría yo elegido otro término para señalar el carácter complejo de la mente humana, la nota de reflexión como la más importante y distintiva, más la integración dentro de ella del hombre total. Pero a esto me referiré al hablar de la sede de la razón. Si bien he señalado en la definición el aspecto práctico de la RAZON, no de la razón práctica como distinta (es una y misma la razón, no sólo como facultad, sino como operación: lo teórico conlleva siempre en alguna forma una dinámica práctica), voy sin embargo, en parte por la limitación del tiempo, a cargar el énfasis en la razón teórica.

\section{C. - LAS CONDICIONES DE LA RAZÓN}

Sin detenerme en mayores análisis explicativos o justificativos, enumero ciertas notas, que o se desprenden de la índole misma de la razón o la rodean como circunstancias en el mundo.

1) La RAZÓN es autónoma. Esta autonomía, que no significa desvinculación y ausencia de compromiso, dimana como un PROPRIUM (para hablar con terminología escolástica) de su capacidad ir restricta de juzgar. La razón tiene sus propias leyes dimanadas de sí misma. La razón es instancia, que en último término no tiene instancia. Nada puede imponerse al juicio de la razón, si no es la propia razón, que revisa sus juicios. De fuera pueden venir elementos de juicio, sugestiones para modificarlo o perfeccionarlo, nada más: el juicio final tiene la razón. La autonomía significa también que ningún campo del saber le está vedado por una decisión externa de la razón. Es decir que la actividad de la razón es la antítesis del dogmatismo, entendido este como la imposición no razonada e irrevisable de premisas de pensamiento.

2) La RAZÓN está comprometida con la verdad. He explicado el sentido de autonomía. Esto no sólo no implica desentendimiento irresponsable, sino más bien atadura mayor. Esta paradoja aparente se clarifica más que con explicaciones abstractas con un ejemplo y con una comparación. El hombre libre y pensante es ser más comprometido que el animal. El juez, si por un lado debe estar totalmente libre de interferencias para el fallo, por otro se halla como el que más, atado a la equidad. La gran atadura de la RAZÓN es la verdad con todo lo que de coherencia, dinamismo 
inquisitivo, sinceridad, etc., supone. El compromiso con la verdad plantea al hombre racional (podemos decir a la razón, sin descender a la disquisición de qué porción pertenezca a la razón y cuál a la voluntad) tarde o temprano una gran opción ante ella, y así surgen los elementos éticos y heroicos de la verdad, que con tanta insistencia señalaron los griegos, sobre todo Platón. El hombre de la razón puede, y debe de algún modo, ser el MÁRTIR de la verdad al estilo de Sócrates. Surgen aquí mil factores de calidad humana como el valor, la generosidad, el desinterés quijotesco. Podemos, glosando a Kierkegaard con su caballero de la fe, hablar del caballero de la razón.

3) La RAZÓN es crítica. La raíz de la crítica es la reflexión; la crítica es la forma más acendrada de juzgar: la razón retorna sobre sus conocimientos y dictamina respecto a ellos (crítica). Por lo demás la CRÍTICA es la forma cabal de ejercer la autonomía. Y de ejercer constantemente el compromiso con la verdad.

4) La RAZÓN es dialéctica. Uso el término dialéctica en su sentido primordial: el proceso del diálogo. La razón está obligada a dialogar en muchas formas: dialoga consigo misma, en el proceso constante de ensanchar y criticar sus conocimientos; la razón dialoga con el mundo externo en otro proceso constante de recibir, y dar. Pero, sobre todo, la razón dialoga con la razón: el ser humano es esencialmente social, por tanto todas sus formas son truncas si se repliega sin más sobre sí como individuo. Esta "socialidad" esencial tiene que manifestarse en manera preclara al tratarse de lo más específico suyo: la razón. Dialogar de razón a razón además de necesidad esencial, es el gran medio para enriquecer y perfeccionar el conocimiento racional. En este diálogo existe un código, cuyo mandato fundamental es la búsqueda desinteresada de la verdad. El gran peligro, que opaca y pervierte el diálogo, es olvidar esta norma, para manipular indebidamente la verdad. El diálogo desemboca en la última condición de la RAZÓN.

5) La RAZÓN es práctica. Desinterés y no manipulación de la verdad no significan que el hombre debe ser testigo estático del mundo y su acontecer. El hombre debe, fiel al dictamen y reglas de juego de la razón (contra ellos atentaría la manipulación de la verdad), gobernar al mundo, perfeccionarlo y perfeccionarse a sí mismo. Toda expresión de la razón, aun la más abstracta, tiende a una praxis (yo no soy partidario de la división tan dicotómica entre razón teórica y práctica). ¿Cómo se ha de conducir la praxis a fin de que esta no resulte esclavizante y destructura de sectores 
humanos?: gravísima pregunta. Sin duda una de las soluciones, quizás la más importante, sería la del diálogo de las razones con miras a una praxis.

\section{3.-UNIVERSIDAD, SEDE DE LA RAZÓN}

\section{A) Breve definición de Universidad}

En modo paralelo a la "definición" de razón, no pretendo elaborar en forma escolar una definición, intento más bien subrayar determinadas notas. Hago por cierto omisión de la historia de la Universidad, me refiero a tal como se presenta hoy. Adoptamos como referencia hipotética la definición, por cierto preñada de perplejidades de contenidos conceptuales, de que Universidad es un centro de alta docencia e investigación para servicio de la sociedad. A partir de esto hagamos un análisis apretado de cuál sea la versión existencial de estos centros de alta docencia e investigación, con miras por supuesto a esclarecer el tema. Cada vez más va acentuándose, al menos de palabra, la distinción Universidad técnica y Universidad humanística. La Universidad técnica estaría llamada a atender al área de las ciencias no humanas (física, matemática, etc.) y a su aplicación mediante la técnica. La Universidad humanística tendría la incumbencia de estudiar al hombre como un hecho integral multifacético, y a la vez ejercer una función crítica de la sociedad como fenómeno humano. Hay una tendencia, al menos en ciertas esferas, a menospreciar a la Universidad humanística, ya sea por considerar que se ha "saturado su propio mercado" (perdóneseme la expresión), ya sea por considerarla sede de la garrulería y fortín de la agitación política inmediatista.

No faltan hechos que dan pie a tamaña afirmación. Pero una actitud así no puede venir sino del mediocre, incapaz de percibir el papel crítico de la mente humana y la misión integral del hombre.

Básicamente doy por válida la distinción, si bien rechazo el exceso dicotómico. La Universidad humanística debe o puede integrar en su torno los otros niveles de la ciencia, para iluminarlos desde la visión del hombre; pero no entremos en este punto. 
Enfrentados así dos tipos de Universidades, sería conveniente diversificar los términos (es siempre saludable hacerlo). Por razones históricas y por sentido de la palabra (universalidad y a la vez unidad), el vocablo Universidad tiene que ser rescatado para la Universidad humanista. A la otra habría que buscar una denominación apropiada.

Hecho esto, habrá que concluir que a estas dos modalidades de centros superiores, deben corresponder dos manifestaciones de la razón. Así retorno en parte a algo que afirmé al comienzo.

A la Universidad humanística corresponde la visión y estudio integral del hombre integral; por ende es solio de actividad mental, así mismo integral, enfocada al hombre como integrado en sí por la mente. Debido a esta interpretación del quehacer UNVERSITARIO, no soy partidario de calificarla como solio de la RAZÓN. Preferiría acudir a términos como pensamiento, sabiduría, etc. La Universidad sería una Sedes Sapientiae. El otro tipo de la Universidad, en el que la razón como dianoia propia del pensar matemático tiene amplísimo campo, sería la Sedes Rationis. De paso piénsese que la computación está sustituyendo a la actividad matemática humana. En cambio - creo yo - una computadora reflexiva jamás se dará. Pues bien, dicha máquina maravillosa está mejor sentada en una Politécnica que en una Universidad. De todos modos conservo el término razón.

\section{B) El compromiso de la Universidad con la razón: vincula- ción histórica}

A partir de este punto lo que diga no será sino aplicaciones sencillas y obvias de todo lo afirmado anteriormente.

Desde aquellos gérmenes de Universidades, que fueron las escuelas griegas (el peripato, la stoa, etc.), la Universidad se constituye como con nota especificante en Sede de la razón. Sede en sentido doble: el lugar (físico y espiritual) en que la razón circula y actúa como en su propia casa, el lugar en que la razón ocupa el centro de honor y el cetro, que dirige todo el quehacer.

La Universidad medieval, que nace vinculada a la catedral (la cátedra), pretende integrar en su seno todo el saber humano. Así constituyese ya en sede de la razón. La sujeción de la Universidad medieval a la revelación cristiana, si bien crea un problema, una crisis (no se puede negar), de ninguna manera significa una 
negación de la razón o de sus leyes. Hay gran esfuerzo por dar una explicación racional al acto inicial de la fe: se busca dar armonía constante a los postulados de la revelación y a las exigencias de la razón. Todo ello se sintetiza en la célebre frase anselmiana: "fides quaerens intellectum" (escribió S. Anselmo un libro intitulado PROSLOGIUM SEU FIDES QUAERENS INTELLECTUM).

A partir de la edad moderna la Universidad no sólo es sede de la razón, sino de las razones. Y al decir esto me refiero a las grandes escuelas filosóficas que, en una u otra forma prosperaron, se debatieron, se sintetizaron en la Universidad. La Universidad se convierte en la gran intérprete del mundo y del hombre a la luz de la razón, en la buscadora de las últimas explicaciones: todo ello en un clima de autonomía del pensar. Y esto ha seguido así pese a ofuscaciones o ataduras esporádicas de la razón.

\section{C) El compromiso intrínseco de la Universidad con la ra- zón y sus condiciones.}

No sólo por el hecho histórico ya mencionado, sino por la naturaleza misma de la Universidad, la cual pretende desde la mente humana interpretar e integrar al hombre total, ella se constituye en el centro antonomástico, en que reside y actúa la razón. No hay duda en ello; no es sino un asunto de relación de conceptos. Alguien puede decir: ¿Por qué la Universidad y no otra institución se arroga este privilegio? En fin de cuentas nos hallamos ante una discusión verbal, que requiere una digresión breve.

La Universidad no en cuanto vocablo sino en cuanto contenido (puede haberse llamado Academia, Alma Mater), y en su constitución esencial, es una necesidad del ser humano histórico, habida cuenta de su socialidad. Suele distinguirse entre sociedades naturales y optativas. Las naturales surgen de un requerimiento de la propia naturaleza humana. Se dice que tal es el caso de la sociedad civil y de la familia. Sin entrar en discusiones laterales, y admitida como válida la distinción entre sociedad natural y optativa, estimo que entre las dos debe interponerse la sociedad existencialmente necesaria. Está claro que hay una diferencia notoria entre Universidad y un Club de Leones: éste sería tal vez una típica sociedad opcional, aquella una sociedad postulada por una exigencia al menos histórica del ser humano. Aunque se suprimieran las "Universidades", los hombres de determinado nivel de civilización, seguirán reuniéndose, para dialogar sobre el mundo, el hombre y sus raíces. El diálogo tenderá a sistematizarse y 
buscará alguna fórmula de institución: es decir habrá surgido el núcleo de la Universidad.

Dicho esto, resulta mucho más interesante elucubrar sobre las condiciones de la RAZÓN aplicadas a la Universidad. Habíamos señalado cinco de ellas, sin pretender que sean las únicas. Analicémoslas dentro de la Universidad. Es lástima que la estrechez de espacio no me permita sino abrir pequeñas trochas para ampliaciones y discusiones ulteriores.

1) Una Universidad tiene que ser sede de la autonomía de la razón. Para ello tiene en primera instancia que garantizar la libertad interna. La autonomía se ahoga con frecuencia más desde dentro de la Universidad que desde fuera. La única norma válida para impedir una actitud universitaria sería lo antirracional o subracional de la misma. Entiendo por subracional el proceso mental que parte de fórmulas (y las usa) como el slogan, la mentalización en base de afirmaciones simplistas, la consigna dorada con visos de crítica. Salvada la autonomía de los enemigos internos, la Universidad se defiende de las amenazas externas. Estas son múltiples y se vinculan con intereses de los grupos de poder: económicos, políticos en el sentido más restricto de la palabra. Ahí debe afirmarse la Universidad como el gran ejemplo de dignidad humana y debe mantener con toda entereza su compromiso con otra de las condiciones de la razón: la fidelidad a la verdad. La autonomía como libertad de la razón en diálogo justifica las demás autonomías: administrativa, económica, de inviolabilidad predial. Creo en este punto que con valor tenemos que revisar el concepto de autonomía. Hay dos factores que pueden empañarla y la empañan de hecho: confundir autonomía con aislamiento, interpretar y usar la autonomía no como la libertad de la razón, sino como una intangibilidad basada en las otras autonomías, para fines por ejemplo de acción política inmediatista. Luego hablaré de lo político en la Universidad. Por el momento afirmo que una actividad constante de política inmediatista es un atentado a la razón tal como ésta debe actuar en la Universidad. No olvidemos que la autonomía de la razón crea un gran compromiso. Si usamos las autonomías derivadas, para eludirlo y trabajar a servicio de otros compromisos, la Sociedad despreciará a la Universidad y tarde o temprano le exigirá cuentas.

2) La Universidad se compromete con la verdad como compromiso de la razón. Como he dicho, esta es la gran limitación de la libertad, que supone la autonomía, Y en esto recalco el aspecto 
ético y heroico de tal compromiso. Hay formas de heroísmos; todas ellas caben en la Universidad. El normal, el de todos los días, al fin el más importante, es del esfuerzo gris por esclarecer en diálogo a la razón. Dicho esclarecimiento reviste caracteres concretísimos, y se llaman excelencia académica, rigor científico, etc. No faltarán momentos (y esto lo ha probado la historia de las Universidades de América Latina) en que la institución o determinado hombre universitario tenga que vivir el aspecto heroico del compromiso con la verdad. Ello puede darse cuando la obligación para con la razón crítica o la razón práctica vuelvan necesariamente político el quehacer universitario y con esto levante la reacción de las fuerzas que luchan por el poder. Surge entonces la imagen de Sócrates.

3) El compromiso con la razón crítica es importante hoy. Aunque resulte incómodo para quienes preconizan un funcionamiento técnicamente mecanizado de la sociedad y aunque exista el peligro de la demagogia ligera so color de crítica. La Universidad tiene que defender su derecho a la crítica. Esta, como en el caso de la razón ha de comenzar por sí misma: revisar constantemente sus objetivos, sus grandes planteamientos, sus métodos, sus logros, para luego avanzar en la dirección y dentro del dinamimo de la razón. Y aquí vaya una crítica: es triste comprobar el estancamiento de nuestras instituciones universitarias, síntoma de la poca autocrítica renovadora: los mismos planteamientos de hace años, achacosos, por lo anticuados, de vaciedad verbal; métodos viejos; ausencia de proyección hacia el futuro. La Universidad tiene que autocriticarse más, para ejercer su condición de raciocinante. Esto urge tanto más cuanto que el esplendor de esta autocrítica será la mejor garantía del peso y la veracidad de la crítica del exterior. De las irresponsabilidades universitarias en este punto, puede ir surgiendo en la gente la desconfianza primero en la Universidad y luego en la razón. Se dará entonces una de las graves crisis de la razón en sentido socio-histórico: pensar que no deben ser los caballeros de la razón sino los de la fuerza quienes orienten a la sociedad. La crítica externa es el análisis constante de la sociedad en todas sus manifestaciones. Es derecho de la Universidad tanto el ejercerla como el hacerla conocer. Su importancia no requiere ponderación. Es el acto político (si entendemos política como la vinculación con la vida de la polis) eminentemente universitario. Debe llevarse a cabo con enorme rigor bajo las reglas de juego de la razón. Aquí el hombre universitario puede manipular la verdad para intereses que no son de ella ni de la razón. Hay que ser conscientes de la responsabilidad grave que esto encierra. Aun la crítica serena no está exenta de 
reacción beligerante de las fuerzas que luchan por el poder. Entramos así en lo que habíamos hablado del compromiso con la verdad.

4) Al referirme al cuarto punto: la vinculación con la razón dialéctica, basta recapitular lo dicho ya en varias formas: la Universidad practica la razón como cuerpo, en perpetuo diálogo sobre todo entre quienes la conforman. Su empeño tiene que consistir en ser el modelo de diálogo en la razón. Valga la pena aludir a un hecho de aquí (lo concreto y existencial no empaña, sino al revés confirma y dignifica a lo universal y abstracto): este seminario es un símbolo y un síntoma de algo que para mucho bien está sucediendo en nuestro ámbito universitario: el diálogo entre Universidades y entre gente universitaria de diversas posiciones. Esto debe ser altamente fomentado. La cerrazón sectaria es enemiga de la razón y por lo mismo de la Universidad.

5) Resta considerar el compromiso de la Universidad con la quinta condición de la razón: su referencia a la práctica. He insistido en que la preocupación de este artículo era la razón teórica. Casi preferiría dejar este punto importantísimo sin ni siquiera tocar. El solo es tema suficiente de todo un seminario. Su importancia se acrecienta, si pensamos (tal es mi parecer) que la gran crisis actual de la Universidad brota primordialmente de la razón práctica: o esta se relega a un rincón, convirtiéndose la Universidad en la torre de marfil típica, o se dan a la praxis formas no universitarias que terminan por perjudicar a la razón sin más. De todos modos señalo puntos, que por sí son elocuentes. a) La praxis en la Universidad debe ser siempre gobernada por la propia Universidad, es decir que ella debe fijar las metas, los métodos, etc., y tener el mando racional del proceso. En el orden práctico, y atenta la psicología de las masas, el peligro de la persona o grupo operante es el de, a fuerza de atender a la inmediatez de la acción, olvidar las metas y convertirse en instrumento de otros fines y otras personas. La razón práctica debe funcionar en íntima relación con la circunstancia suprema de la razón teórica, la cual reside automáticamente en la Universidad.

b) Como consecuencia de lo anterior la praxis de la Universidad ha de revestir características universitarias aun en las manifestaciones externas.

c) La razón práctica, sin excluir efectos inmediatos, tiene que tener en mucho el carácter de lo mediato: es propio de lo racional la mediatez precisamente por ser refleja. La espontaneidad sensible produce reacciones inmediatas y con ellas efectos inmediatos. Revestida de paciencia la Universidad tiene que meditar su obrar, debe planearlo, debe medirlo en toda su complejidad y sus alcances. De esta manera nos hallaremos ante una razón práctica auténticamente universitaria. Quede para otra ocasión el análisis de lo político en el obrar práctico universitario. Este trabajo no es sino una presentación fragmentaria del gran tema propuesto. Espero que sea de utilidad para impulsar el diálogo de la Universidad y entre las Universidades. 